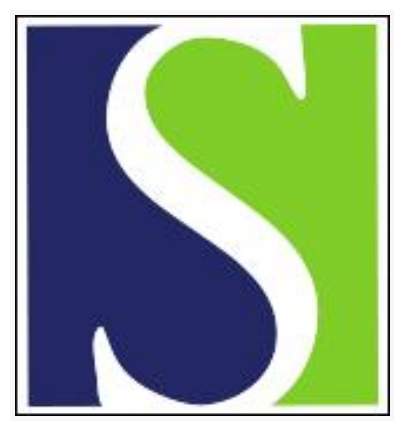

Scand J Work Environ Health 1998;24(5):321-333

https://doi.org/10.5271/sjweh.352

Issue date: Oct 1998

Psychosocial aspects of stress, health and safety on North Sea installations

by Parkes KR

The following article refers to this text: 2002;28(1):64-71

Key terms: age; health behavior; job characteristic; mental health; occupational stress; offshore oil and gas installation; personality; psychosocial factor; review; shift work

This article in PubMed: www.ncbi.nlm.nih.gov/pubmed/9869303

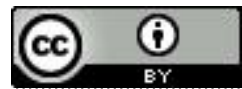




\title{
Psychosocial aspects of stress, health and safety on North Sea installations
}

\author{
by Katharine $R$ Parkes, $P h D^{\prime}$
}

\begin{abstract}
Parkes KR. Psychosocial aspects of stress, health and safety on North Sea installations. Scand $J$ Work Environ Health 1998;24(5):321-333.

In recent years, the North Sea oil and gas industry has been exposed to widespread change, including organizational restructuring, "down-sizing", and increased safety regulation. This article reviews the literature on psychosocial stress, health, and safety among offshore personnel in the light of these developments. Few studies directly compare onshore and offshore populations; the available data suggest that, relative to their onshore counterparts, offshore personnel experience greater anxiety, more sleep problems, and higher work load. Within the offshore population, objective factors (eg, size, age, type of installation, work patterns, and occupational differences), subjective work perceptions, individual differences (age and personality), and health behavior, all play significant roles in relation to health and safety outcomes. However, much of the research in stress and health offshore has methodological limitations and does not allow causal interpretation. The need for prospective studies of the longterm mental and physical health of offshore personnel, and for research in several specific areas, is noted.
\end{abstract}

Key terms age, job characteristics, health behavior, mental health, occupational stress, offshore oil and gas installations, personality, psychosocial factors, shift work.

Work on offshore installations is widely regarded as stressful in its impact on the health and life-style of offshore personnel, and also on their spouses and families. Potential sources of stress include the remote and isolated location of many offshore oil and gas installations, the adverse physical environment, the confined work and living conditions, the lack of privacy, perceived hazards of offshore work and the helicopter travel it necessitates, demanding shift patterns, fluctuating work load with alternating boredom and high activity, separation from family and local community, and family problems associated with "intermittent husband syndrome" $(1-7)$. Stressors such as these have adverse implications for physical and psychological health, although offshore employment also has favorable aspects, such as enhanced pay rates, relatively long periods of leave, restrictions on smoking and alcohol, the availability of offshore health services, and a relatively early retirement age (8). In spite of these potential benefits, the demands and constraints inherent in offshore work are considered to be a significant source of psychosocial stress.

In recent years, the offshore work environment has been the subject of both descriptive and empirical research. Descriptive approaches $(9,10)$ provide qualitative insights into offshore work and its meaning to the personnel concerned; in contrast, empirical research (the subject of the review) emphasizes quantitative evaluation of the physical and psychosocial stressors to which offshore employees are exposed and their impact on health, safety, and work effectiveness. Early empirical research in this area, including the pioneering work of Hellesøy (2) and Sutherland \& Cooper (11), has been reviewed elsewhere $(6,12)$. However, offshore work conditions have changed markedly in recent years, and studies based on data collected in the 1980 s do not reflect the extensive changes that have taken place in the North Sea oil and gas industry during the 1990s.

In particular, the Cullen report on the Piper Alpha disaster (13) led to significant improvements in offshore safety regimes, including modifications to structures, procedures, and regulations, and a formal requirement for operating companies to produce detailed "safety cases". Moreover, newer installations tend to be smaller and to operate with greater automation and fewer personnel than those of earlier generations, a trend likely to be accelerated by current technological developments. Other recent changes in the industry include downward fluctuations in oil prices and falling production levels in older fields. These circumstances have necessitated cost-reduction measures, including widespread "down-sizing" and redundancies, while greater efficiency and flexibility have been demanded of the remaining work force. On some

1 Department of Experimental Psychology, University of Oxford, Oxford, United Kingdom.

Reprint requests to: Dr KR Parkes, Department of Experimental Psychology, University of Oxford, South Parks Road, Oxford, OX1 3UD, United Kingdom. [E-mail: kathy.parkes@psy.ox.ac.uk] 
installations the duration of offshore tours has also been extended in a further attempt to reduce costs. Thus the industry has undergone a period of rapid change, with implications not only for improved safety and productivity, but also for job insecurity, work load, and dissatisfaction. Consequently, there is a need for an up-to-date review of psychosocial stress and health among North Sea personnel. The present article seeks to meet this need, bringing together within an established theoretical framework (14) findings from a variety of studies, including an offshore survey carried out in 1995-1996 (15). First, however, to set the review in context, an introductory section outlines relevant background information about the North Sea oil and gas industry and its work force.

\section{Background}

North Sea oil and gas production, and the exploration and drilling operations that support it, employ a substantial work force. In the United Kingdom (UK) sector of the North Sea, the work force has averaged more than 30000 personnel over the past 5 years (16), while recent statistics indicate that there are approximately 25000 offshore employees in the Norwegian sector (17). In both countries, the North Sea industry plays a vital role in the national economy; thus the productivity, health, and safety of its employees is a matter of considerable importance.

\section{Demographic factors and work patterns in the offshore industry}

Recent survey data suggest that less than $3 \%$ of the UK offshore work force are female $(15,18)$ as compared with $16 \%$ of Norwegian offshore personnel (17), and that, within an overall age bracket of 19-65 years, 70\% of the UK offshore employees are in the age range of 30 50 years. Personnel in a wide variety of occupations (including management, technical, production, and maintenance work), together with administrative, catering and ancillary staff, are employed offshore. Of the 1600 respondents ( $83 \%$ response rate) surveyed by Parkes (15), $36 \%$ of those working on production platforms were employed by the operating companies, while the remainder were contractors. However, on drilling rigs, the majority of personnel $(75 \%)$ were directly employed by the company operating the rig. Educational qualifications varied widely among the survey respondents: degrees (7\%), technical qualifications $(53 \%)$, and secondary school certificates (23\%). Only $17 \%$ of the sample had no formal qualifications. The typical work pattern reported was $12-$ hour shifts (alternating with 12-hour rest periods) over a period of 2 weeks, followed by 2 weeks' shore leave. Approximately half the respondents worked a day-night rotating shift pattern; most of the others worked day shifts.

\section{Occupational health services offshore}

The remoteness of many installations, the difficulty of obtaining emergency assistance from onshore, and the expense of medical evacuation necessitate provision of comprehensive occupational health services offshore. Thus each installation has a designated sickbay, equipped to deal with medical emergencies, accidents, and routine health problems. A qualified "medic" is employed on each installation; if required, advice is available around the clock from onshore medical staff. Horsley \& MacKenzie (18) have noted that, in terms of occupational health provision, offshore personnel are in a more favorable position than most UK employees.

\section{Medical standards for offshore work and the "healthy worker" effect}

Applicants for offshore work must pass a medical examination to ensure that they are physically and mentally fit to meet the demands of the North Sea environment and the training in survival and fire-fighting techniques that such employment requires. In the United Kingdom, the relevant medical standards are set out in detailed guidelines (19), which exclude applicants with a wide range of physical and psychiatric conditions that would not necessarily be a bar to onshore employment. Consequently, many applicants who would be medically accepted for onshore jobs are not accepted for offshore work. Continued employment offshore is subject to regular medical checks (every 3 years, 2 years, or annually, for employees under 40 years, $40-50$ years, and over 50 years of age, respectively).

The general standard of health among offshore personnel is therefore considerably higher than that of comparable onshore workers. While the familiar healthy worker effect $(20,21)$ implies that, as a result of both initial selection and survival in employment, the working population will show better health than those not employed, offshore personnel form an exceptionally "healthy worker" group with more favorable health status, both physical and mental, than the general onshore working population. The high medical standards required of offshore employees, also noted in the Statfjord study (2), are particularly relevant when observed health differences between onshore and offshore employees are considered.

\section{Theoretical framework}

The present review of psychosocial aspects of offshore health and safety has been structured by reference to an established theoretical model of work stress, the "Michigan model" (14). This model incorporates the main types of psychosocial variables that have been examined in the 
offshore environment and the pathways by which they are related. The processes by which objective stressors give rise to short-term effects (affective, cognitive, behavioral, and physiological responses) and to longer-term outcomes (eg, cardiovascular disease) are represented as a complex path diagram incorporating direct effects and mediated pathways by which the causal influence of objective stressors is transmitted through one or more subjective variables. However, environmental factors (eg, organizational structure, management style, social support) and individual differences also influence the causal sequence. Categories of individual difference variables that affect responses to job demands include demographic characteristics, personality, coping styles, and biomedical factors (22). These individual differences may operate at several points in the stress process, for example, by influencing selection into different types of jobs, by influencing subjective perceptions of the work environment, or by affecting stress responses, either directly or as moderator variables.

Adopting this theoretical framework, the present article reviews research into psychosocial stress and health offshore, identify gaps in the current literature, and note relevant methodological issues. Most of the studies reviewed are concerned with factors predictive of health and safety outcomes within the offshore population; such studies serve to highlight environmental variables and personal attributes associated with adaptation to a demanding work situation. First, however, in the light of the issues discussed in previous sections, the extent to which overall differences in health have been observed in comparisons of onshore and offshore groups is considered.

\section{Comparison of onshore and offshore groups}

Although some long-term prospective studies of health and mortality in the petroleum industry have been reported $(23-26)$, these studies do not allow disease rates to be compared between onshore and offshore employees. In the absence of such studies, it is inherently difficult to separate the effects of favorable health status among offshore personnel from the potentially adverse health effects of the environmental demands to which they are exposed. Thus a cross-sectional comparison of health outcomes in onshore and offshore groups does not allow unambiguous interpretation. However, such comparisons do provide information about the patterns of health problems experienced in the 2 environments. The main focus of studies comparing onshore and offshore groups has been mental health, assessed by standard symptom checklists such as the General Health Questionnaire (GHQ) (27), although other health-related outcomes, including sickness absence, have also been examined.

\section{Mental health}

Cooper \& Sutherland (28) state that, as compared with published normative data, "a disturbingly high proportion of offshore workers score high levels of free-floating anxiety [p 122]". In contrast, in a separate study, only employees at the highest offshore job level were found to be more anxious than comparable onshore personnel (1); at other job levels, onshore-offshore differences in anxiety and depression were not significant. These discrepant findings may be attributable to sample characteristics and data collection methods. Addressing these methodological issues, a subsequent study compared GHQ scores of onshore and offshore personnel, all of whom were engaged in similar production work, thus removing possible confounding due to job differences in onshore and offshore groups (3). The offshore group had significantly higher overall symptom levels than the onshore group; nonetheless, the symptom levels of the offshore group were closely similar to those in a cross-sectional sample of men employed in onshore industry (29).

As already discussed in this review, as a result of medical screening, offshore employees are a particularly healthy group of workers relative to the onshore working population. Evidence also suggests that offshore personnel are significantly biased towards "stable extravert" personality characteristics (30), usually associated with above-average mental health. The fact that, in spite of favorable health status and adaptive personality traits, the offshore group did not show low symptom levels similar to those in the onshore group suggests that psychosocial stressors in the offshore environment may play a significant role in mental health. Higher work load offshore, as compared with onshore, was a relevant factor (30), but further analyses demonstrated that the elevated anxiety scores offshore were largely attributable to symptoms such as "felt constantly under strain", "been getting scared or panicky for no good reason", and "been feeling strung up and nervous all the time" (3). Thus the offshore environment appears to give rise to feelings of pervasive tension and apprehension, rather than more to specific anxiety. A variety of psychosocial and physical stressors, which do not apply onshore, may account for these anxiety symptoms, which are consistent with responses to "threat" situations more generally (31).

\section{Psychosomatic complaints and sleep problems}

Scores on a psychosomatic symptom checklist developed for use in process industries (32) showed that, consistent with their favorable health status and younger age, offshore operators tend to report fewer minor health complaints than their onshore counterparts (30). In contrast, a significantly higher proportion $(54 \%)$ of the offshore group than the onshore group (36\%) reported sleep problems. However, more detailed analysis of sleep patterns in relation to day-night shift work suggested that offshore 
installations may provide a more favorable environment for nightshift adaptation than the domestic surroundings of onshore personnel (33).

\section{Sickness absence}

Relatively few studies of sickness and absence among offshore employees have been reported, but data collected in 1985 indicated that absence rates among offshore personnel in the Norwegian sector were considerably lower (2.4\% of workhours) than those in the Norwegian work force as a whole (6.0\%) (34). Medical screening of offshore employees could partially account for this difference. However, the use of formal personnel records for analyzing sickness and absence rates is complicated by the fact that offshore employees are regarded as being at work if they are on board the installation, even if temporarily not able to carry out normal duties through injury or illness. Thus short-term absence, which contributes significantly to onshore statistics, does not normally appear on offshore records. As reported in the Statfjord study (2), $76 \%$ of offshore employees visiting the sickbay returned to work, $14 \%$ were given time off but remained on the installation, and only $14 \%$ were sent ashore (some persons initially given time off were later sent ashore). Similarly, a recent study found that only $18 \%$ of a sample of 917 offshore personnel reported any absence from work in the previous 6-month period (35).

Significant relationships exist between number of days of absence due to illness and ratings of physical and psychosocial factors offshore $(34,36)$. The strain of coping with adverse work conditions may give rise to illness, but causal direction is unclear in these data. However, absence from work, whatever its cause, is damaging to individual morale and to organizational productivity. Recognition of the financial cost of absence has led to the development of preventive programs designed to reduce absence due to sickness and improve psychological well-being among onshore oil industry employees (37), and health promotion programs of this kind could also be applied offshore.

\section{Stress and health offshore in relation to objective environmental factors}

Several objective aspects of the environment are relevant to the well-being of offshore personnel. First, physical characteristics of installations, such as size and type (eg, drilling versus production) predict psychosocial outcomes. Second, temporal patterns of offshore work (particularly work-leave cycles and shift rotation patterns) are important in relation to well-being, especially sleep, among offshore personnel. Third, job factors, such as type of work and hierarchical level, are associated with different perceived work characteristics and with different health outcomes. Although an examination of objective factors directly in relation to health and safety outcomes disregards the mediating role of subjective perceptions, such studies can provide potentially valuable information for operating companies and offshore medical personnel and serve as a basis for developing more sophisticated research models.

\section{Physical characteristics of offshore installations}

Evidence suggests that location, size, and type of installation are associated with psychosocial outcomes among offshore personnel. Examining these factors in a series of univariate analyses, Sutherland (38) reported that installations in the southern sector of the North Sea (as compared with those in the more remote northern and central sectors), fixed platforms (as compared with drilling rigs), and smaller installations (as compared with larger ones) were associated with more favorable mental health. The age of offshore installations is also related to satisfaction among offshore employees (36). Thus personnel working on the newest of 3 platforms in the Statfjord field reported greater satisfaction than those on the older ones. This finding can be attributed in part to improved design standards, more extensive recreational facilities, and better living accommodation, which tend to alleviate stress on newer installations. Furthermore, newer installations usually have more advanced emergency alarm systems and escape equipment, which may serve to reduce anxiety associated with potential hazards. However, these findings do not allow causal interpretation; in particular, new installations can attract (often from an existing work force) highly motivated and adaptable personnel, and selection effects of this kind may contribute to the favorable responses which tend to characterize employees on newer platforms.

Interpreting findings from univariate analyses poses further problems if the predictor variables are correlated; for example, recently-commissioned platforms tend to be smaller than those designed in the 1980 s, thus potentially confounding age and size. Multivariate methods in which installation size, age, and type are examined simultaneously allow more precise interpretation. One such analysis, based on data from male offshore personnel $(\mathrm{N}=1462)$, showed that physical installation characteristics were significant independent predictors of perceived stressors and health-and-safety-related outcomes (15). On production installations, age and size were significantly related to satisfaction with safety measures, newer or larger installations being more favorable than older or smaller ones. Platform age was also significant in relation to physical stressor scores (older platforms having higher levels of physical environment stressors), while platform size predicted perceived work load, 
levels being higher on larger platforms than on smaller ones. However, in general, the physical characteristics of the installations accounted for less variance in outcome than psychosocial factors.

\section{Work schedules and shift patterns}

Shift rotation. Onshore research highlights the potentially adverse health effects of shift work as compared with day work $(39,40)$. Evidence also suggests that adverse health effects are apparent in both past shift workers and those currently working shifts $(41,42)$ and that prolonged exposure to shift work over a period of years has cumulative adverse effects on sleep patterns and health, not accounted for solely by increasing age $(33,43-45)$. On North Sea installations, personnel involved in round-theclock activities (eg, production, maintenance, and drilling) are not only exposed to 12 -hour shifts and demanding work, but also to the need for circadian adjustment to day-night shift changes. The scheduling of day-night shifts poses particular difficulties offshore as rotation patterns are constrained by the necessity of helicopter travel to and from the installation and the limited accommodation available.

The most common rotation pattern in the North Sea is one in which a shift change occurs at the midpoint of the 2-week tour, night work usually being scheduled for the first week. Consequently, personnel have to adapt to night work on arrival offshore and to re-adjust back to day work after 7 night shifts, in some cases with no more than a 5-hour break between the last night shift and the first day shift. A potentially more favorable pattern in which shift rotation takes place on alternate tours (either 14 days or 14 nights being worked on any one tour), although successfully implemented on some installations, has not been widely adopted in the UK sector.

Lauridsen et al (46) used a wide range of self-report health indicators, including measures of sleep disturbance, use of sleeping medication, headaches, muscular tension, and stomach problems, to examine the health implications of North Sea shift patterns. Shift patterns involving rotation tended to show a poorer profile on the health-related measures than nonrotating patterns, the least favored rotation pattern being $0000-1200$ and $1200-2400$. Many of the personnel working this pattern experienced problems associated with the demanding circadian adjustment required. A recent study of offshore personnel compared day work and day-night rotating shift work in terms of minor health problems, taking into account the fact that work patterns tend to be confounded by job types (eg, production and drilling often involve rotating shifts, whereas other jobs, eg, administration, typically involve only day work); sleep disturbance and gastric problems were found to be predicted by day-night shift work, but not by job type, whereas the opposite was true of musculoskeletal problems and headaches (15).
However, health is not the only important aspect of shift scheduling; alertness and performance are equally crucial issues. The effects of shift rotation on mood and cognitive performance (reaction time, memory, and reasoning) changes over the offshore work cycle have also been examined (47). In this study, personnel were assessed (using computer-based tests) 3 times during each of nine 12-hour shifts spaced over the 2-week period. The shift rotation conditions examined were 14 days, 14 nights, 7 days followed by 7 nights, and 7 nights followed by 7 days. Consistent with other data (46), shift patterns that involved a midcycle shift change showed significantly poorer profiles of subjective alertness, sleep, and performance during the second week as compared with the corresponding "fixed shift" (ie, 14 days or 14 nights) patterns.

Further evidence of the effects of shift rotation among offshore personnel comes from a recent study in which levels of excreted melatonin were compared over a 2week dayshift sequence and a 2 -week nightshift sequence (48). The results showed that adjustment to night work occurred within the first week, but the authors noted the potential for increased accident risk during this adaptation period. The implications for shift schedules which impose a midcycle shift change, thus requiring further circadian adaptation at the end of the first week, are clear. From a health and safety point of view, therefore, a strong argument can be made for implementing "fixed shift" rotation patterns; however, offshore personnel much prefer the 7 nights- 7 days pattern, which allows them to go on leave adjusted to a normal circadian cycle at the end of each tour.

Work-leave cycles. Offshore work-leave cycles have few direct equivalents in onshore industry, although the analogy with Australian "fly-in" mines has been noted (49). Most offshore personnel work rotas based on 2-week offshore duty periods, usually alternating with 2-week shore leaves ( $2-2$ pattern). However, $3-3$ rotas ( 3 weeks of offshore work alternating with 3 weeks of leave) are becoming more common, and service personnel (who provide short-term specialist assistance offshore) often have very irregular schedules depending on operational requirements. In spite of the diversity of offshore work patterns, almost all the existing literature on health and psychosocial factors among North Sea personnel relates to persons working $2-2$ schedules; only rarely have different offshore work-leave patterns been compared in terms of the health and performance of personnel. One such study, carried out on drilling rigs in the Caspian Sea (50), examined the physiological effects of work-leave patterns. On the basis of the results the authors recommended 1-week, rather than 2-week, work-rest cycles. In the North Sea, 3-3 work-leave patterns are widely disliked, although the limited data available provide 
little evidence of cumulative fatigue effects on measures of daily mood (51).

Empirical studies in the onshore industry are also relevant to long workhours offshore. In particular, Proctor et al examined the effects of overtime hours on cognitive performance among automotive workers (52). After control for possible confounding variables, overtime hours were found to predict impaired performance on several tests of attention and visual-motor skills. The results showed that 20 hours overtime (ie, a total of 60 hours work in 7 days) gave rise to substantial performance decrements, ranging from $9 \%$ to $46 \%$ for the various tasks examined. Furthermore, measures of negative mood were directly related to overtime hours and to the number of consecutive days worked. These findings should be seen in the context of the standard 84-hour week worked offshore; indeed, nearly $40 \%$ of offshore personnel report working more hours than the standard week, with $13.8 \%$ (mostly management personnel) reporting an excess of 100 hours of work in 7 days (15). The long hours worked offshore raise serious questions about cumulative fatigue, performance decrement, and impaired well-being among offshore management personnel.

\section{Occupational groups}

Measures of the perceived work environment, job satisfaction, and health among offshore personnel differ significantly among occupational groups $(2,46)$. Personnel working in different offshore jobs also differ in risk perceptions, in satisfaction with safety, and in accident experience (5). Similarly, after control for confounding variables, offshore personnel in 8 job types were found to differ significantly in perceived work load and other job dimensions, job satisfaction, future prospects, risk perceptions, and minor health problems (15). Two occupations, management and catering, imposed particularly high levels of demand and time pressure. The managers also reported high autonomy, skill, and variety in their work, but catering lacked these favorable characteristics and represented a particularly "high strain" job in terms of the demand-discretion model of work stress (53).

\section{Stress and health offshore in relation to perceived work characteristics}

Studies based on objective environmental characteristics (such as installation size and age or occupational group) allow offshore groups that may be at risk of work-related health impairment to be identified. However, to understand the pathways by which objective work conditions have an impact on the well-being of offshore personnel, it is also necessary to assess the subjective perceptions and appraisals of the personnel concerned. Although several studies focusing on subjective work perceptions among offshore employees have been published $(2,28,46,54)$, only rarely have the more complex intermediate pathways involved in the stress process been examined $(5,30)$. Both physical and psychosocial stressors play a significant role in these processes.

\section{Physical environment stressors}

The North Sea environment exposes personnel to physical stressors such as noise, vibration, poor lighting and ventilation, confined living accommodation and work space, and adverse weather conditions. Ratings of noise and other environmental stressors correlate with measures of psychological well-being (2), and perceived work load may mediate these relationships (55). However, the extent of exposure to adverse physical conditions offshore differs across occupational groups, construction and drilling crews reporting the highest exposure levels (15). In this study, exposure to physical stressors partially explained the incidence of minor health problems, especially headaches, in different job groups. Physical stressor ratings also varied with job level, those in the higher job grades reporting less exposure than those in basic grades. In particular, managers generally worked in office accommodation, removed from the physical stressors experienced by operating personnel.

\section{Psychosocial stressors}

High levels of psychosocial stressors are typically associated with adverse health outcomes. Significant stressors identified in the offshore literature include job characteristics, perceived risks, job insecurity, and concerns about work and family relationships $(15,28,30,46,55)$.

Job characteristics. Perceived job characteristics, such as work load, variety, clarity, control, and social support, contribute to observed links between job types and measures of health and job satisfaction. Thus the job perceptions of offshore personnel differ across occupational groups $(2,15,46)$, and these differences partially account for levels of well-being and job satisfaction among personnel in different jobs, perceived clarity and variety being particularly important in this respect (15). In contrast, relations between job type and anxiety were primarily mediated by work load, but low job clarity also played a significant role.

Perceived risk. The extent to which personnel consider themselves to be at risk in the offshore environment is a significant factor underlying stress and anxiety. Several types of offshore hazards can be distinguished. For instance, Marek et al (56) identified the 6 hazard dimensions of major threats (eg, fires, explosion, and blow-out), 
weather conditions, destruction of the installation, falling objects, cargo handling, and general safety. These dimensions were associated with different organizational factors and specific safety resources, including personnel training and safety equipment. Rundmo examined subjective risks in relation to organizational factors, stress, and accidents offshore (55). An analysis of 1990 data indicated that offshore safety measures and risk perceptions, together with physical work conditions and job characteristics, were all implicated, directly or indirectly, in psychological symptoms among offshore personnel, while objective risk (in terms of accident and nearaccident rates) was related to both perceived risk and job stress.

More recent findings reflect the higher priority now given to offshore safety. Thus, as compared with the 1990 findings, data obtained in 1994 showed a lower proportion of personnel who felt at risk offshore, a higher proportion satisfied with safety and contingency measures, and reduced levels of stress (57). However, these overall comparisons do not reveal the wide differences that exist in the extent to which different installations are perceived as safe by the personnel on board. Both platform size and platform age are related to satisfaction with safety measures, the newest and the largest platforms having the most favorable ratings (15). Significant differences in safety ratings were also found between personnel in different jobs; consistent with other safety literature (58), the safety of specific work activities (eg, drilling, deck operations) was found to be rated more highly by those with first-hand knowledge of that activity than by other personnel. Satisfaction with safety predicts mental health over and above the effects of age, neuroticism, and other control variables (15), suggesting that confidence in the safety of the work environment is an important factor in the general well-being among offshore personnel.

Job insecurity. Analyzing data collected in the 1980s, Sutherland \& Cooper ( 7 ) identified a factor representing concerns about career prospects and job security among offshore personnel, topics that have become increasingly contentious in the 1990s. Recent data highlights the dissatisfaction of offshore employees with current job security and future prospects; these concerns are particularly marked among men aged $40-45$ years, among those at lower job levels, and among those on smaller, older installations (15). Contrary to earlier findings (2), in these data, operating company personnel showed greater dissatisfaction with job security and prospects than those employed by contractors. In addition to the "downsizing" of operating companies (with consequent redundances, and deteriorating career prospects for those who remain), a significant proportion of personnel previously employed by operating companies are now contractors, while others fear the imposition of such a change in the future. These structural changes may explain the current pessimism of operator personnel. Job insecurity, and economic stress more generally, has been found to have a negative impact on employee health $(59,60)$. Increased work load is also relevant in this context; in a follow-up study of oil industry personnel, both onshore and offshore, work load showed a highly significant increase between 1990 and 1995, and this increase partially accounted for the increase in anxiety over this period (61).

Work-family interface. Among many offshore personnel and their families, the intermittent absence from home of one partner for periods of two or more weeks is a significant source of stress. Coping with repeated partings and reunions, managing the disruption of family and social life, and the difficulties of joint decision-making imposes demands on both partners. The problem of "intermittent husband syndrome" and the impact of offshore work on family life have attracted considerable research attention. (See, eg, references 2, 9, 62-64.) For instance, Morrice et al (64) found that offshore wives reported mood and behavioral changes linked to the pattern of partings and reunions, $10 \%$ experiencing particularly severe problems. Most seriously affected were those with preschool children, and no previous experience of husband absence, and those with outside employment (63).

The issue of work-family relationships among offshore personnel is important to the oil and gas industry as a whole, in that family concerns and the conflicts associated with partner absence may spill over into the work situation, impairing mental health $(28,54)$ and work efficiency (65) and thereby potentially endangering the safety of offshore installations. This matter remains important, particularly because of the current interest shown by some operating companies in extending the 2 -week offshore tour to 3 weeks, thus potentially increasing the pressures on family relationships (51).

\section{Individual differences in relation to demographic and personality variables}

Individual differences, particularly demographic and dispositional characteristics, are significant factors in work adaptation, which act as overall predictors of well-being or as moderators of work environment effects $(22,31$, 54 ). Findings relevant to the offshore industry are reviewed in the following sections.

\section{Age}

Over the past 30 years, North Sea oil and gas has grown from a new enterprise employing a relatively young work force into a mature industry, with a corresponding 
increase in the age profile of employees. This trend has been accentuated by economic changes that have resulted in decreased recruitment and fewer opportunities for older personnel to transfer to onshore work. Currently, a high proportion of offshore personnel are in the 40-45 years age group although there is significant variation across job types and installations (15). While the industry views the increasing age profile of offshore personnel with concern, research findings present an ambiguous picture (66). On one hand, older offshore employees are less likely to visit the sickbay (2) and tend to report fewer health problems than their younger counterparts (67); they also report greater job satisfaction than those in the middle age ranges (15). On the other hand, older workers have more difficulty adjusting to shift work, not only onshore (39), but also in the offshore environment (33). Furthermore, age is positively related to the proportion of medical evacuations necessitated by illness rather than injury (68). The increasing age profile of offshore personnel, coupled with life-style and dietary patterns, has led some authors to suggest that cardiovascular disease is likely to become a serious problem in this occupational group in the future $(18,69)$.

\section{Dispositional measures}

Type A behavior. High type A scorers are characterized by achievement striving, impatience, hostility, irritability, and job involvement; this personality pattern tends to be associated with health impairment, including cardiovascular symptoms (70). Among offshore personnel, workers high in type A behavior are more likely to report psychological distress and accident involvement than those with low scores (54). Furthermore, the "speed and impatience" type A component is related to anxiety among offshore personnel, but not among those in similar jobs onshore, and this relationship is accentuated by age. Thus older, high type A's working offshore report the highest level of anxiety $(21,71)$. In contrast, the "achievement motivation" component of type $\mathrm{A}$ is positively related to offshore job satisfaction. The additional constraints and regulations to which workers living and working offshore are exposed relative to those working onshore may explain the anxiety findings, while opportunities for more challenging and varied work offshore probably account for the link between job satisfaction and achievement motivation offshore.

Extroversion and neuroticism. The dimensions of extroversion (sociable, active, and adaptable behavior) and neuroticism (vulnerability and pessimism) are strongly linked to stress resilience and psychological health (72). Evidence suggests that offshore personnel are higher in extroversion and lower in neuroticism than normative population samples $(15,30)$, a combination of traits normally associated with above-average mental health. Extroversion has been found to relate to self-reported accident involvement offshore although not to perceived stressors, while neuroticism directly predicted both perceived stressors and accident involvement (54). Findings such as these may contribute to the identification of personnel at particular risk of accident involvement.

Other dispositional characteristics. Little information currently exists about how individual adjustment to the North Sea environment is influenced by other dispositional characteristics. For instance, locus of control (the extent to which people believe that effort and ability, rather than fate or chance, determine success and rewards in life), hardiness, and coping styles are important determinants of responses to life and work stress generally (31). These dispositional variables may be particularly relevant in adaptation to the constrained and demanding work conditions experienced offshore.

\section{Health behavior}

While the material in the present review focuses primarily on environmental factors in relation to well-being among offshore employees, individual life-style and health behavior is also significant. Evidence suggests that offshore personnel may be less careful than onshore groups about following advice relating to smoking, use of alcohol, diet, and exercise and consequently may be at greater risk of health impairment. Indeed, the demands of the North Sea environment, the nature of offshore work, separation from family, and the importance of meals as an opportunity for socializing may all accentuate the tendency for offshore personnel to adopt an unhealthy life-style.

\section{Smoking}

The proportion of smokers among offshore personnel tends to be higher than in the general male population. Thus, in recent studies, $36.3 \%$ and $37.2 \%$ of the male offshore population were found to be smokers $(15,18)$, as compared with $31 \%$ for men in the United Kingdom, and $34 \%$ for men in Scotland (73). However, there were significant differences in smoking rates between occupational groups offshore. Thus $25.3 \%$ of production operators reported smoking as compared with $44.1 \%$ and $48.1 \%$ of construction and drilling workers, respectively; in general, operating company personnel were less likely to smoke $(27.3 \%)$ than contractors (40.7\%) (15). Social class effects (74), work in a stressful environment (75), and the availability of duty-free cigarettes offshore (18) may all contribute to the smoking patterns observed. 


\section{Alcohol}

A total ban on alcohol on offshore installations is strictly enforced. However, excessive use of alcohol by some employees while on shore leave, with residual effects after their return to the installation, was reported in the $1980 \mathrm{~s}(11,76)$, and current findings suggest that alcohol consumption among the offshore work force remains relatively high. In a recent study, $32 \%$ of offshore workers claimed to drink more than 21 units of alcohol a week (18), as compared with $24 \%$ of the general male population in Scotland (73). Although empirical evidence of excessive drinking during shore leave is scarce, anecdotal accounts suggest that "binge" drinking shortly before returning offshore may impair the safety and quality of work during the first few days of a tour $(2,12)$. More seriously, 7 cases of alcoholic psychosis were diagnosed among 78 cases of mental disorders necessitating medical evacuation from offshore installations over a 5-year period (68).

\section{Diet, obesity and exercise}

Evidence reported in the 1980s highlighted the need for greater health awareness among offshore personnel, particularly in relation to body weight, diet, and exercise habits. Thus Light \& Gibson found that $40.1 \%$ of an offshore sample were overweight according to a standard classification system and an additional $5.5 \%$ were obese; these incidences were significantly higher than in the comparison sample (77). In addition to the health risks of obesity, overweight offshore workers may have difficulty in climbing stairs and negotiating narrow walkways, and may also be a liability in emergencies (78).

Unhealthy eating patterns and the provision of meals every 6 hours (to cover day and night shifts) are probable factors underlying obesity among offshore personnel. Research in the Norwegian sector, in which 203 offshore personnel were asked about their food intake over the previous 24-hour period, showed that the average daily intake was $12.2 \mathrm{MJ}$ (approximately $3000 \mathrm{kcal}$ ), $44 \%$ of which came from fats, 39\% from carbohydrates, and 17\% from protein, figures that were consistent with food purchase records (69). Excess intake of fats was particularly marked, averaging nearly $50 \%$ more than the maximum recommended value ( $30 \%)$. The extent of energy expenditure among offshore employees is also relevant in relation to dietary intake. Some occupational groups (eg, drillers and deck crews) expend considerable energy in the course of their work, but others have relatively sedentary jobs. Although many North Sea installations provide gymnasiums, evidence of the extent to which such facilities are used is mixed $(18,77)$.

However, as compared with the 1980 s, more attention is now given to encouraging "healthy eating" offshore, and personnel recognize the need to improve their $\operatorname{diet}(18)$. Norwegian research suggests that between 1985 and 1993 eating patterns offshore changed in the direction recommended by the National Nutrition Council and that health promotion information played a part (79). The value of health promotion and fitness testing is also highlighted by the results of a "life-style program" introduced in 1992 by a major North Sea operating company (80).

\section{Objective health data in relation to medical evacuations and sickbay visits}

Further information about the health of offshore personnel can be obtained from an analysis of formal records related to medical evacuations and sickbay consultations. These records complement self-report survey data in providing a source of objective, independent information about the types of health problems occurring in the offshore environment.

\section{Medical evacuations}

An analysis of 790 medical evacuations due to illness (based on 1976-1984 data from the UK sector) showed that the most frequent cause was disorders of the digestive system (about half of which were dental problems) (30\%), followed by musculoskeletal ( $20 \%)$, respiratory $(15 \%)$, nervous system $(12 \%)$, mental, including stressrelated problems $(5 \%)$, and cardiovascular $(5 \%)$ problems; the remaining $13 \%$ was accounted for by a range of other disorders (81). Among the evacuations due to injuries, fractures, sprains, and strains were the most common causes, accounting for $43 \%$ of the total. The authors also reported that the proportion of illness evacuations rose relative to the proportion of injury evacuations over the 8 years of the study. A similar finding was reported more recently (68); in this case, injury evacuations fell from $53 \%$ in $1978-1988$ to $36 \%$ in $1991-$ 1992, while the proportion due to illness increased correspondingly. Improvements in safety regimes, on the one hand, and an aging offshore work force, on the other, could account for these findings. This study also identified a temporal pattern of medical evacuations in relation to the offshore work cycle. The highest incidence of illness requiring subsequent evacuation occurred on the first day offshore (suggesting that some personnel were commencing their tour while unfit), whereas the highest frequency of injury evacuation was on the 4 th or 5 th day of the tour.

\section{Sickbay visits}

Records of sickbay visits provide further information about patterns of illness and injury offshore. Anderson $\& \operatorname{Cox}(82)$ identified reasons for sickbay consultations as follows: $40 \%$ for medical cases, $10 \%$ for skin 
problems, $5-10 \%$ for minor trauma, 5-10\% for musculoskeletal problems, $1-15 \%$ for ear, nose and throat problems, and $10-15 \%$ for eye problems. In the Statfjord study (2), somatic complaints accounted for $47 \%$ of the total sickbay visits, accidents and injuries for $16 \%$, and personal concerns for $15 \%$. In terms of specific diagnoses, musculoskeletal disorders were the most frequent, accounting for $25 \%$ of the sickbay visits. There appears to be little information about the temporal patterns of sickbay visits in relation to the offshore work cycle, although it has been noted that the peak in medical consultations tends to occur 3 days after arrival offshore (83).

\section{Limitations of survey research}

It is clear from the material reviewed that significant empirical associations exist between measures of physical and psychosocial work conditions offshore and measures of health outcomes. In addition, comparable onshore and offshore employees differ in perceptions of their work and in health measures. In theoretical models of stress, work conditions are seen as playing a causal role in relation to health, work perception, acting as a mediator of relations between objective work demands and health measures (14). However, it is important to recognize that the methods used in much of the research cited do not allow the nature or direction of causal influences to be identified. Cross-sectional data provide only an instantaneous "snapshot" of conditions at one time. Thus the effects of work conditions cannot be distinguished from effects due to the selection and survival of particular types of individuals in the offshore environment. Furthermore, effects associated with physical installation characteristics or with different occupations may be confounded by unmeasured differences in demographic, psychosocial, or organizational factors.

Associations between self-reports of work perceptions and health are particularly vulnerable to a variety of interpretations; in particular, negative affectivity (the tendency to view both self and environment in a negative light) tends to inflate correlations between measures of the perceived work environment and mental health. Only in a few offshore studies have statistical methods been used to control these spurious effects $(15,54)$. An additional problem is that surveys rarely achieve a complete or near-complete response from the target population; indeed, response rates as low as $25-40 \%$ are not uncommon when questionnaires are sent out by mail (28, 54,84 ), although in some studies substantially higher response rates have been achieved $(5,15)$. Individuals who respond to such surveys tend to differ from those who do not; thus low response rates may give rise to unrepresentative findings.

\section{Conclusions and areas of further research}

North Sea personnel play a crucial role in the oil and gas industry, the success and productivity of which contribute significantly to economic prosperity. Considerable research effort has been directed towards understanding the physical and psychosocial stressors experienced by offshore personnel, and their implications for well-being. Thus offshore personnel are exposed to work patterns (including long duty hours, arduous shift patterns, higher work load, greater task complexity and variety, and less co-worker and family support) significantly more demanding than those of onshore personnel; evidence also suggests that they experience higher anxiety than their onshore counterparts. Within the offshore population, objective factors, the perceived work environment, and individual differences in age and personality all play significant roles in relation to health and safety outcomes. A considerable number of offshore personnel reports minor health problems and psychological distress, a small proportion is involved in serious health emergencies requiring medical evacuation (either through illness or accident), and the life-style and health behavior of this occupational group gives cause for concern. However, causal evaluation of the mental and physical health effects of offshore work is complicated by the high medical standards required for North Sea employment and the current lack of prospective studies.

Thus existing research findings provide only a starting point for considering the impact of work conditions on the health and safety of offshore personnel. The following areas particularly merit further attention:

- Long-term studies of the mental and physical health of North Sea personnel could provide more reliable information than is currently available about the health effects of offshore work. In addition to prospective studies, such as those carried out in the petroleum industry, if the biomedical data collected during routine medical examinations could be made accessible to researchers, they would provide a valuable resource for examining the long-term health impact of offshore work. Regular computer-based health and fitness monitoring of offshore personnel, currently being introduced by some operating companies, could also serve a similar purpose.

The increasing age profile of the offshore work force requires that more attention be given to the impact of offshore work on the performance and health of older offshore personnel. In particular, it is important to discover whether offshore work, and day-night shift rotation in particular, has cumulative ill-effects on health over and above those solely due to age.

- In recent years, the oil and gas industry has undergone major structural changes, among the main effects of which have been down-sizing, redundancies, and job 
insecurity. Remaining employees have been exposed to additional demands both quantitative (eg, increased work load) and qualitative (eg, multiskilling) in nature. Research in the oil industry has yet to document the health effects of these changes, although the damage to the morale and security of the work force is widely recognized.

- Evidence suggests that the health, performance, and sleep patterns of offshore shift workers are impaired relative to those of dayshift personnel; patterns of shift rotation are also important. Drill crews are exposed to particularly demanding conditions, usually working a $0000-1200$ and $1200-2400$ shift rotation pattern rather than the more favorable 0600-1800 and 18000600 schedule. Drilling is physically and mentally demanding, and often carried out in a noisy and cold environment. In all these respects, the work situation of this occupational group could be improved, and would merit research attention.

- Few recent studies have focused on "work-family interaction" among offshore personnel, although the increased proportion of women now working outside the home may intensify the problems of "intermittent husband absence". Furthermore, although women still make up only a small proportion of the UK offshore work force, their numbers are likely to increase in the future, and the particular problems of the work-family conflict experienced by women who work offshore have not yet been adequately addressed.

Finally, it should be emphasized again that the topics outlined here, and other aspects of psychosocial research offshore, cannot be adequately studied by relying solely on cross-sectional survey data. In recent years, scientists in more general areas of stress research have increasingly recognized the need for longitudinal data and for a wider range of outcome measures. In the future, it is important that studies of psychosocial factors in the offshore work environment also focus greater attention on the use of more sophisticated research methods and longitudinal designs.

\section{Acknowledgments}

This review was based on literature I obtained while carrying out research funded by the UK Health and Safety Executive, Offshore Safety Division.

\section{References}

1. Gann M, Corpe U, Wilson I. The application of a short anxiety and depression questionnaire to oil industry staff. J Soc Occup Med 1990;40:138-42.
2. Hellesøy OH, editor. Work environment: Statfjord field. Bergen (Norway): Universitetsforlaget, 1985.

3. Parkes KR. Mental health in the oil industry: a comparative study of onshore and offshore employees. Psychol Med 1992;22:997-1009.

4. Parkes KR. Work and well-being among offshore oil employees. In: Collett P, Furnham A, editors. Social psychology at work. London: Routledge, 1995:124 41.

5. Rundmo T. Associations between safety and contingency measures and occupational accidents on offshore petroleum platforms. Scand J Work Environ Health 1994;20:128-31.

6. Sutherland VJ, Cooper CL. Occupational stress in the offshore oil and gas industry. Int Rev Ergon 1989;2:183-215.

7. Sutherland VJ, Cooper CL. Stress in the offshore oil and gas exploration and production industries: an organizational approach to stress control. Stress Med 1996;12:61-78.

8. Sunde A. Psychosocial aspects of offshore work. In: Safety and health in the oil and gas extractive industries. London: Commission of European Communities, 1983:176-87.

9. Solheim J. Coming home to work: men, women and marriage in the Norwegian offshore oil industry. In: Lewis J, Porter M, Shrimpton M, editors. Women, work and family in the British, Canadian and Norwegian offshore oilfields. London: Macmillan Press, 1988:140—62.

10. Alvarez A. Offshore: a North Sea journey. London: Hodder \& Stoughton, 1986.

11. Sutherland VJ, Cooper CL. Man and accidents offshore - an examination of the costs of stress among workers on oil and gas rigs. Colchester (England): Lloyd's of London Press, 1986.

12. Sutherland KM, Flin RH. Stress at sea: a review of working conditions in the offshore oil and fishing industries. Work Stress 1989;3:269-85.

13. Lord Cullen. The public enquiry into the Piper Alpha disaster, London: Her Majesty's Stationery Office, 1990.

14. Israel BA, Baker EA, Goldenhar LM, Heaney CA, Schurman SJ. Occupational stress, safety, and health: conceptual framework and principles for effective prevention interventions. J Occup Health Psychol 1996;1:261 - 86.

15. Parkes KR, Clark MJ. Psychosocial aspects of work and health in the North Sea oil and gas industry, part IV: the offshore environment in the mid-1990's: a survey of psychosocial factors. Sudbury (England): HSE Books, 1997.

16. Department of Trade and Industry. The energy report: Vole 2. London: Her Majesty's Stationery Office, 1996.

17. Kontoret for arbeidsmarkedsanalyse. Sysselsettingen i petroleumsrettet virksomhet [Employment in petroleum-related activites]. Oslo: Arbeidsdirektoratet: 1998.

18. Horsley HD, MacKenzie IG. Lifestyle survey amongst North Sea oil workers. Paper presented at the HSE/UKOOA conference Occupational Health Offshore, Aberdeen, Scotland, March, 1996.

19. UK Offshore Operators Association. Guidelines for medical aspects of fitness for offshore work. London: UK Offshore Operators Association, 1995

20. Choi BCK. Definition, sources, magnitude, effect modifiers, and strategies of reduction of the healthy worker effect. J Occup Med 1992;34:979-88.

21. Arrighi HM, Hertz PI. The evolving concept of the healthy worker survivor effect. Epidemiology 1994;5:189-96.

22. Parkes KR. Personality and coping as moderators of work stress processes: models, methods, and measures. Work Stress 1994;8:110-29.

23. Christie D, Robinson K, Gordon I, Bisby J. A prospective 
study in the Australian petroleum industry, I: mortality. Br J Ind Med 1991:48:507-10.

24. Christie D, Robinson K, Gordon I, Bisby J. A prospective study in the Australian petroleum industry, II: incidence of cancer. Br J Ind Med 1991;48:511-4.

25. Tsai SP, Dowd CM, Cowles SR, Ross CE. Morbidity patterns among employees at a petroleum refinery. J Occup Med 1991;33:1076-80.

26. Tsai SP, Gilstrap EL, Colangelo TA, Menard AK, Ross CE. A mortality study of oil refinery and petrochemical employees. J Occup Environ Med 1997;39:448—54.

27. Goldberg D. Manual of the general health questionnaire. Windsor (England): NFER Publishing Company, 1978.

28. Cooper CL, Sutherland VJ. Job stress, mental health, and accidents among offshore workers in the oil and gas extraction industries. J Occup Med 1987;29:119-25.

29. Banks MH, Clegg CW, Jackson PR, Kemp NJ, Stafford EM, Wall TD. The use of the General Health Questionnaire as an indicator of mental health in occupational studies. J Occup Psychol 1980;53:187-194.

30. Parkes KR. Human factors, shift work, and alertness in the offshore oil industry: part I (a survey of onshore and offshore control-room operators) and part II (alertness, sleep, and cognitive performance). London: Her Majesty's Stationery Office, 1993.

31. Lazarus RS, Folkman S. Stress, appraisal and coping. New York (NY): Springer Publications, 1984.

32. Vaernes RJ, Knardahl S, Romsing J, Aakvaag A, Tonder O, Walther $\mathrm{B}$, et al. Relations between environmental problems, psychology and health among shift-workers in the Norwegian process industry. Wotk Stress 1988;2:7-15.

33. Parkes KR. Sleep patterns, shift work, and individual differences: a comparison of onshore and offshore control-room operators. Ergonomics 1994;37:827-44.

34. Iversen E. Health, sick leave and work organization on a Norwegian oil field. In: Johnston, M, Herbert M, Marteau T, editors. European health psychology: proceedings of the 4 th Annual Conference of the European Health Psychology Society. Leicester (England): British Psychological Society, 1991:56-57.

35. Ulleberg P, Rundmo T. Job stress, social support, job satisfaction and absenteeism among offshore oil personnel. Work Stress 1997;11:215-28.

36. Iversen E, Marek J, Hellesøy OH. Work environment Statfjord field: physical work environment. Bergen (Norway): Research Center for Occupational Health and Safety, University of Bergen, 1986. Report no 4

37. Tuinman CP. Cost-effectiveness of occupational health programmes. Paper presented at the HSE/UKOOA conference Occupational Health Offshore, Aberdeen, March, 1996.

38. Sutherland VJ. Understanding individual differences in safety performance. In: Storey K, Shrimpton M, editors. Social, psychological and cultural aspects of health and safety in the offshore oil industry. St Johns (Canada): Memorial University of Newfoundland, Institute of Social and Economic Research, 1993:21-49.

39. Monk TH, Tepas DI. Shift work. In: Cooper CL, Smith MJ, editors. Job stress and blue collar work. Chichester (England): Wiley, 1985:65-84.

40. Åkerstedt T. Psychological and psychophysiological effects of shift work. Scand J Work Environ Health 1990;16 suppl 1:67-73.

41. Frese M, Semmer N. Shiftwork, stress, and psychosomatic complaints: a comparison between workers in different shift- work schedules, non-shiftworkers, and former shiftworkers. Ergonomics 1989;29:99-114

42. Vener KJ, Szabo S, Moore JG. The effect of shift work on gastrointestinal (GI) function. Chronobiologia 1989;16:421 39.

43. Foret J, Bensimon G, Benoit O, Vieux N. Quality of sleep as a function of age and shift work. In: Reinberg A, Vieux N, Andlauer P, editors, Night and shift work: biological and social aspects. Oxford: Pergamon Press, 1981:149-60.

44. Knutsson A, Akerstedt T, Jonsson BG, Orth-Gomer K. Increased risk of ischaemic heart disease in shift workers. Lancet 1986;2(8498):89-92.

45. Knutsson A. Shift work and coronary heart disease. Scand J Soc Med Suppl 1989;44:1-36.

46. Lauridsen O, Tronsmoen S, Berland J, Gitlesen JP, Ringstad AJ, Pedersen TH, et al. Shift-work and health: shift-work, sleeping difficulties, psychosocial work environment and psychosomatic complaints. Stavanger (Norway): Rogaland Research, Phillips Petroleum Company, 1991.

47. Parkes KR, Clark MJ, Payne-Cook E. Psychosocial aspects of work and health in the North Sea oil and gas industry, part III: sleep, mood, and performance in relation to offshore shift rotation schedules. Sudbury (England): HSE Books, 1997.

48. Barnes RG, Deacon SJ, Forbes MJ, Arendt J. Adaptation of the 6-sulphatoxymelatonin rhythm in shiftworkers on offshore oil installations during a 2-week 12-h night shift. Neurosci Lett 1998;241:9-12.

49. Shrimpton M, Storey K. Work-related stress in the Newfoundland offshore oil industry: implications for health and safety. In: Storey K, Shrimpton M, editors. Social, psychosocial and cultural aspects of health and safety in the offshore oil industry. St John's (): Memorial University of Newfoundland, Institute of Social and Economic Research, 1993:1-20.

50. Alekperov II, Melkumyan AN, Zamchalov AI. Some peculiarities of the physiological validity of shift work schedules for the crews of floating oil drilling platforms. J Hyg Epidemiol Microbiol Immunol 1988;32:385-96.

51. Parkes KR, Clark, MJ. Psychosocial aspects of work and health in the North Sea oil and gas industry, part V: offshore work/leave schedules: data analyses and review. London: Health and Safety Executive, 1997.

52. Proctor SP, White RF, Robins TG, Echeverria D, Rocskay AZ. Effect of overtime work on cognitive function in automotive workers. Scand J Work Environ Health 1996;22:124 32.

53. Karasek RA, Theorell T. Healthy work: stress, productivity, and the reconstruction of working life. New York (NY): Basic Books, 1990.

54. Sutherland VJ, Cooper CL. Personality, stress and accident involvement in the offshore oil and gas industry. Pers Indiv Diff 1991;12:195-204.

55. Rundmo $T$. Risk perception and safety on offshore petroleum platforms, part II: perceived risk, job stress and accidents. Saf Sci 1992;15:53-68.

56. Marek J, Iversen E, Helles\{bf\}y OH. Risk, organization and safety on an oil platform. In: Singleton WT, Hovden J, editors. Risk and decisions. New York (NY): Wiley, 1987:12337.

57. Rundmo T. Experience of risk and safety in Norwegian offshore workers: changes in risk perception in the period 1990 to 1994. Paper presented at the conference The Role of Risk Perception in Safety Management in the Workplace, Robert Gordon University, Aberdeen, February 1995.

58. Sjöberg L, Drottz-Sjoberg BM. Knowledge and risk percep- 
tion among nuclear power plant employees. Risk Anal 1991;11:607-18

59. Fenwick R, Tausig M. The macroeconomic context of job stress. J Health Soc Behav 1994;35:266-82.

60. Reynolds JR. The effects of industrial employment conditions on job-related distress. J Health Soc Behav 1997;38:105-16.

61. Parkes KR, Razavi TDB. Psychosocial aspects of work and health in the North Sea oil and gas industry, part II: a five-year follow-up study (1990-1995) of offshore and onshore personnel. Sudbury (England): HSE Books, 1997.

62. Clark D, Mccann K, Morrice K, Taylor R. Work and marriage in the offshore oil industry. Int J Soc Econ 1985;12:36-47.

63. Taylor RC, Morrice K, Clark D, McCann K. The psychosocial consequences of intermittent husband absence: an epidemiological study. Soc Sci Med 1985;20:877-85.

64. Morrice JK, Taylor RC, Clark D, McCann K. Oil wives and intermittent husbands. Br J Psychiatry 1985;147:479-83.

65. Evans $\mathrm{P}$, Bartolomé $\mathbf{F}$. The changing picture of the relationship between career and family. J Occup Behav 1984;5:921.

66. Parkes KR. Psychosocial aspects of work and health in the North Sea oil and gas industry, part I: review of the literature. Sudbury (England): HSE Books, 1997.

67. Parkes KR. Lifestyle, work, and individual factors as predictors of psychosomatic complaints among offshore employees. Paper presented at the 14th World Congress on Psychosomatic Medicine, in Cairns, Australia, September 1997.

68. Horsley HD. Study of medical evacuations from offshore installations: five year report, 1987-1992. Sudbury (): HSE Books, 1997.

69. Oshaug A, Østgård LI, Trygg KU. Diet among oil-workers on off-shore oil installations in the Norwegian sector of the North Sea. Br J Nutr 1992;68:11 $\rightarrow$ 9.

70. Ganster DC, Schaubroeck J, Sime WE, Mayes BT. The nomological validity of the Type A personality among employed adults. J Appl Psychol 1991;76:143—68.

71. Parkes KR. Stress, work, and health: the role of individual differences. In: Bittles AH, Parsons PA. editors. Stress: evolutionary, biosocial and clinical perspectives. London: Macmillan Press Ltd, 1996:113-51.

72. Eysenck HJ, Eysenck SBG. Manual of the Eysenck personality questionnaire. London: Hodder \& Stoughton, 1975.
73. Scottish Home and Health Department. Health in Scotland, 1991. London: Her Majesty's Stationery Office, 1991.

74. Cox BD, Blaxter M, Buckle AJL, Fenner NP, Golding JF, Gore M, et al. The health and lifestyle survey. London: Health Promotion Research Trust, 1987.

75. Caplan RD, Cobb S, French JR. Relationships of cessation of smoking with job stress, personality, and social support. J Appl Psychol 1975;60:211-19.

76. Aiken GJM, McCance C. Alcohol consumption in offshore oil rig workers. Br J Add 1982;77:305-10.

77. Light IM, Gibson M. Percentage body fat and prevalence of obesity in a UK offshore population. Br J Nutr 1986;56:97 104.

78. Cox RAF, Norman JN Some special problems. In: RAF Cox, editor. Offshore medicine: medical care of employees in the offshore oil industry. 2nd ed. London: Springer-Verlag, 1987:89-107.

79. Oshaug A, Helle-Bjonnes C, Bugge KH, Bjorge-Loken E Nutrition promotion and dietary change at offshore oil installations in the Norwegian sector of the North Sea. Eur J Clin Nutr 1995;49:883-96.

80. Lobban P. The Shell Expro Lifestyle programme. Paper presented at the HSE/UKOOA conference Occupational Health Offshore, Aberdeen, Scotland, March, 1996.

81. Norman JN, Ballantine BN, Brebner JA, Brown B, Gauld SJ, Mawdsley J, et al. Medical evacuations from offshore structures. Br J Ind Med 1988;45:619-23.

82. Anderson IK, Cox RAF. Offshore medical care. In: Cox RAF, editor. Offshore medicine: medical care of employees in the offshore oil industry. 2nd ed. London: Springer-Verlag, 1987:61-88

83. Cooper JRB. An employee assistance program in the offshore environment. In: Storey K, Shrimpton M, editors. Social, psychosocial and cultural aspects of health and safety in the offshore oil industry. St John's (Canada): Memorial University of Newfoundland, 1993:140-55.

84. Flin RH, Slaven GM. Managing offshore installations: a survey of UKCS offshore installation managers. Aberdeen (Scotland): Robert Gordon Institute of Technology, 1992.

Received for publication: 5 December 1997 